\title{
O Princípio da Incerteza de Heisenberg pelo Texto Teatral Copenhagen
}

\section{Heisenberg's Uncertainty Principle through the Theatrical Text Copenhagen}

Henrique César da Silva

Mayara de Almeida Barros ${ }^{2}$

\begin{abstract}
'Universidade Federal de Santa Catarina (UFSC), Centro de Ciências da Educação, Departamento de Metodologia de Ensino, Florianópolis, SC, Brasil.

Autor Correspondente: henrique.c.silva@ufsc.br

${ }^{2}$ Universidade Federal de Santa Catarina (UFSC), Programa de Pós-Graduação em Educação Científica e Tecnológica, Florianópolis, SC, Brasil.
\end{abstract}

Resumo: Analisamos o texto da peça teatral Copenhagen, de Michael Frayn, uma conversa pós-morte entre Heisenberg, Bohr e sua esposa Margrette, baseada no encontro dos cientistas em 1941. Envolve os princípios da incerteza e da complementaridade e a participação de Heisenberg na possível construção da bomba atômica alemã. Como dispositivo de análise mobilizamos elementos da dramaturgia, como conflito, gênero drama/épico, indicações cênicas, dramático/ pós-dramático, em seus efeitos de sentido sobre incerteza, dando visibilidade a aspectos materiais desse texto. O princípio de Heisenberg aparece como inspiração para o eixo central de uma estrutura textual que produz diferentes sentidos de incerteza, ligados, metaforicamente, a elementos do princípio da incerteza da Teoria Quântica, produzindo um deslocamento das entidades da microfísica para entidades humanas. Limites epistêmicos associados à ontologia das entidades se transformaram em supostos limites para julgamentos ético-morais. Discutimos implicações para a educação em ciências são discutidas, e apresentamos apontamentos para futuras pesquisas.

Palavras-chave: Educação e teatro; Arte e educação; Princípio da incerteza; Ensino de física; Teoria quântica.

Abstract: We analyzed the text of the play Copenhagen by Michael Frayn, a posthumous conversation among Heisenberg, Bohr and his wife Margrette, based on the meeting of the scientists in 1941. It involves the principles of uncertainty and complementarity and Heisenberg's participation in the likely construction of the German atomic bomb. As an analytical device, elements of Dramaturgy were mobilized, such as conflict, drama/epic genres, scenic indications, dramatic/post-dramatic issues, and their effects on meaning production about uncertainty, by providing visibility to material aspects in this text. The Heisenberg's principle appears as an inspiration for the central axis of a textual structure that produces different meanings of uncertainty, metaphorically linked to elements of the uncertainty principle in Quantum Theory, and produces a displacement of entities from microphysics towards human entities. Epistemic limits associated with the entities' ontology have changed into supposed limits for ethical-moral judgments. The implications for Science Education are discussed, and ideas for future research are presented.

Keywords: Education and theater; Art and education; Principle of uncertainty; Physics teaching; Quantum theory.

Recebido em: 30/07/2020

Aprovado em: 07/10/2020 


\section{Introdução}

A análise de artefatos culturais artísticos que tenham relação com as ciências da natureza pode fornecer importantes subsídios para seu uso e funcionamento em situações de ensino. Tais subsídios, no entanto, dependem do dispositivo analítico utilizado. Se, de um lado, são relevantes análises que enfoquem apenas seus conteúdos, por outro, é importante considerar que a forma tem efeito sobre os conteúdos, e efeito sobre os sujeitos, leitores. Em outras palavras, a forma tem uma dimensão política, porque na medida em que diferencia possibilidades de acesso, leitura, interação, além de também poder ser tomada como conteúdo de ensino e aprendizagem, numa perspectiva interdisciplinar com as áreas de artes e linguagens.

Este trabalho analisou o texto de uma peça teatral intitulada Copenhagen, escrita por Michael Frayn em 1998, tomando a tradução encontrada em Cardoso (2015), a partir de um dispositivo de análise que considera simultaneamente aspectos da forma deste texto teatral e seus conteúdos relacionados à Física. Tratou-se de buscar dar visibilidade a aspectos dessa relação forma e conteúdo, potencializando possíveis mediações num ensino de natureza mais cultural e interdisciplinar.

As relações entre física e teatro vêm sendo apontadas por diversos trabalhos na área como Araujo (2014), Assis et al. (2016), Braga e Medina (2010), Gimenez (2013), Moreira (2012), Oliveira e Gomes (2016) e Silveira (2011). No entanto, a maior parte dos trabalhos tem foco no envolvimento de estudantes com a encenação, ou nos conteúdos das peças, ou mesmo em seus aspectos discursivos, mas não aprofundando os aspectos materiais específicos do texto teatral. Neste artigo, nosso foco recai sobre o texto propriamente dito, ou seja, mobilizando aspectos do campo da dramaturgia, a partir da noção de textualização, tal como apresentada por Silva $(2013,2019)$, a partir de Orlandi (2008) e de autores do campo dos estudos da ciência. Sobre uma análise pautada na noção de textualização, Silva (2013, p. 253) vai apontar que:

\footnotetext{
As análises nesta perspectiva não têm o objetivo de mostrar o sentido do texto (como se este fosse único), ou o sentido 'oculto' ou aquele que estaria nas 'entrelinhas', apesar de desfazer a ilusão do sentido único. Outro resultado importante desse tipo de análise é dar visibilidade a elementos, sem a pretensão de totalidade, que permitem com que a leitura vá nesta direção de sentido. E, como esses elementos funcionam dentro de um contexto histórico-social.
}

Embora sejam vários os aspectos que ligam o texto da peça à Física, para buscar aprofundamento e maior visibilidade das relações forma/conteúdo (textualização), fizemos um recorte num aspecto específico, que, no entanto, se mostrou central na peça: as relações com o princípio da incerteza na Física, proposto por Heisenberg, no contexto da Teoria Quântica.

\section{Aspectos Gerais da Peça Analisada}

São inúmeras as peças teatrais que estabelecem relações diretas ou indiretas com a Física. Entre as mais conhecidas podemos citar A vida de Galileu, de Bertold Brecht, concluída e apresentada em 1943, O caso Oppenheimer, de H. Kipphardt, de 1966, Einstein: a play in two acts, de G. Emanuel, de 1987, entre outras. 
Copenhagen, de Michael Frayn, foi concluída e encenada a partir de 1998. Ficou vários anos em cartaz nos Estados Unidos, e foi encenada em diversos países, entre eles - Brasil, pela companhia teatral Arte e Ciência no Palco (PALMA, 2006). O enredo se desenvolve em torno de uma conversa pós-morte entre Werner Heisenberg, Niels Bohr e sua esposa Margrethe Norlungue, em um espaço não conhecido e num tempo não determinado. Dividida em dois atos, a peça explora o famoso e obscuro encontro entre os

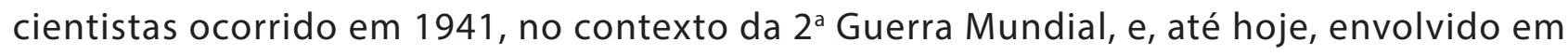
incertezas e especulações. Na época, Heisenberg trabalhava para o programa de pesquisa nuclear alemão, enquanto Bohr e sua esposa, judeus, moravam em Copenhagen, na Suécia então ocupada pela Alemanha nazista. O texto supõe que Bohr e Heisenberg discutiram sobre fissão nuclear e sua possível aplicação para o desenvolvimento de uma bomba atômica. Durante a conversa fictícia os princípios da Complementaridade e da Incerteza, respectivamente propostos por Bohr e Heisenberg, dentro da chamada interpretação de Copenhagen da Mecânica Quântica, aparecem como temas centrais.

São muitos os aspectos da peça que remetem à física. O encontro entre Heisenberg e Bohr é um evento que representa uma importante parceria intelectual na história da Física. Ambos são responsáveis pela interpretação da teoria quântica que se tornou ortodoxa e hegemônica, a chamada interpretação de Copenhagen. Ambos estão entre os mais importantes físicos que contribuíram para a construção da teoria quântica nas décadas de 1920 e 1930. Assim, a peça faz circular um importante episódio na história da ciência. O texto tem inúmeros trechos que remetem à interpretação de Copenhagen, incluindo o princípio da complementaridade e o da incerteza, e divergências filosóficas entre Bohr e Heisenberg. Assim, a peça toca também em aspectos da filosofia da ciência. Além da história da própria Física, o encontro entre eles tem como pano de fundo um importante evento na história, a $2^{\text {a }}$ Guerra Mundial, trazendo elementos de aspectos éticos e políticos relacionados aos trabalhos de cientistas e à produção da ciência. Além de aspectos centrais da teoria quântica, a peça aborda a física nuclear e a construção de reatores e bombas nucleares. A presença da personagem Margrette abre também a possibilidade de remeter a discussões sobre gênero e ciência.

Entre os trabalhos que comentam, analisam e criticam diferentes aspectos da peça, podemos citar o de Silveira, Ribeiro Filho e Silva (2011), que analisam aspectos históricos da teoria quântica relacionados com o texto da peça, além de discutirem as relações entre arte e ciência; Barad (2007), em cuja introdução à sua abordagem filosófica da teoria quântica, faz uma crítica ao modo como a peça aborda as relações entre ética e ciência; Baym (2005), que abordou as analogias encontradas entre a disposição dos atores no palco e o Princípio da Incerteza; Barnett (2005), que abordou a construção das personagens a partir de uma leitura pós-dramática; e Stewart (1999), que avaliou a peça explorando os conceitos científicos através de relações entre forma e conteúdo, bem como a relação entre o uso científico e artístico de metáforas. Neste artigo, no entanto, focamos nos possíveis efeitos de sentidos de incerteza produzidos pelo texto da peça, e suas relações com o princípio da incerteza de Heisenberg.

\section{Aspectos do Princípio da Incerteza de Heisenberg}

Não se trata neste tópico de explicar o princípio da incerteza da teoria quântica na Física, e sim, de chamar a atenção para alguns de seus aspectos que consideramos 
particularmente relevantes no contexto deste trabalho e na relação com o texto da peça. A teoria quântica é uma teoria da física para entidades muito pequenas, da ordem atômica, que apresentam comportamentos experimentais específicos. A ideia de trocas discretas de energia aparecera num trabalho de Planck de 1901 sobre a radiação de corpo negro (interação matéria-radiação). O termo quantum de energia, aplicado à luz, aparecera no artigo de Einstein de 1905 (MARTINS; ROSA, 2014), sobre o efeito fotoelétrico (EINSTEIN, 2005). Os fenômenos físicos macroscópicos podem ser descritos, teórico, experimental e matematicamente, de forma excludente, e para entidades diferentes, ou como transporte de energia, na forma, por exemplo, de radiações, ou como transporte, deslocamento, movimento de matéria. Os primeiros são descritos com equações de onda e os segundos com equações de partículas. Já os fenômenos na escala atômica e subatômica, para as mesmas entidades, podem ser descritos tanto de um modo como de outro, conforme a natureza do experimento. Os sentidos dessas entidades (palavras) na física (ondas, partículas, energia, matéria) estão relacionados com os experimentos realizados, sua descrição matemática e a escala dos fenômenos produzidos nos experimentos. Os experimentos e sua descrição matemática no caso do mundo atômico e subatômico, fazem com que tais palavras e entidades não possam ser perfeitamente compreendidas com os sentidos que chamamos clássicos, ou seja, os sentidos atribuídos a elas quando se referem a fenômenos e experimentos macroscópicos. Entidades antes compreendidas como matéria, ou partícula, porque possuem massa, neste nível de escala atômica e subatômica podem apresentar, conforme o experimento, comportamento ondulatório; entidades antes compreendidas como ondas (radiação), por não possuírem massa, como a luz, por exemplo, podem, conforme o experimento, apresentarem comportamento de partículas. Podemos dizer que a teoria quântica propriamente dita surge quando se encontram equações matemáticas adequadas para descrever tais comportamentos singulares. De modos independentes, Heisenberg e Schröedinger, em 1926, propõem formulações matemáticas diferentes, que posteriormente se mostraram equivalentes.

Vários são os físicos que contribuíram e contribuem ainda hoje para a construção e desenvolvimentos da Teoria Quântica. Bohr e Heisenberg têm papel de destaque por várias razões. Bohr formulou um primeiro modelo atômico que possui elementos além dos requisitados para um tratamento puramente clássico, e que corroborava muito bem com os dados experimentais disponíveis à época. E Heisenberg formulou uma das primeiras descrições matemáticas completas para descrever os comportamentos dessas entidades. Além disso, ambos formularam uma interpretação da teoria quântica recém consolidada, conhecida como interpretação de Copenhagen, composta essencialmente pelos princípios da complementaridade e da incerteza. Embora essa seja apenas uma das interpretações possíveis, ela acabou ganhando hegemonia e sendo mais amplamente divulgada e conhecida entre os físicos. A formulação dessa interpretação é um dos resultados de uma parceria intelectual que gerou vários artigos importantes na física, entremeada por uma estreita amizade. Copenhagen, a cidade em que Bohr morava e trabalhava, era palco para encontros de vários físicos que ali iam trabalhar e debater com Niels Bohr. Num livro de Física em que os aspectos filosóficos são mais explicitamente considerados, como o de Pessoa Jr. (2003), podemos encontrar uma boa explicação da interpretação de Copenhagen em seus princípios. Embora haja uma grande literatura a respeito, optamos por remeter este tópico essencialmente a essa obra, que consideramos, traz os elementos relevantes para nossa argumentação neste trabalho. 
Na segunda metade da década de 1920 vários físicos discutiam por meio de cartas, conversas, publicações em artigos e congressos, a questão das trajetórias de partículas subatômicas como o elétron. Se tais entidades possuem natureza ondulatória, como se pode interpretar que experimentos mostrem trajetórias? Um dos principais experimentos utilizados na época eram as câmaras de Wilson que produziam visibilidade e possibilitava a análise dessas trajetórias.

Para descrever matematicamente trajetórias na física, duas quantidades são fundamentais: q (posição) e p (momento, que inclui a velocidade). Segundo Pessoa Jr. (2003), no final de 1926, Dirac já percebera que "[...] não se pode responder qualquer pergunta da teoria quântica que se refira a valores numéricos para ambos os q e os $p^{\prime \prime}$ (PESSOA JR., 2003, p. 76). No mesmo ano, Heisenberg e Pauli chegam a trocar cartas sobre a questão. Em fevereiro de 1927, então em Copenhagen, Heisenberg se debruça sobre o assunto: "[...] como dar conta das trajetórias lineares de partículas em uma câmara de nuvens de Wilson" (PESSOA JR., 2003, p. 76). E, em final de março termina seu artigo, após conversas com Pauli e Bohr, no qual apresenta suas relações de incerteza. Ainda segundo Pessoa Jr. (2003) é preciso distinguir o princípio da incerteza das relações de incerteza.

O princípio, que se aplica a grandezas não compatíveis entre si (representados por operadores que não comutam, como posição e momento), exprime o fato de que uma maior previsibilidade nos resultados da medição de um dos observáveis implica uma diminuição na previsibilidade do outro. Uma relação de incerteza é qualquer relação matemática que exprima quantitativamente o princípio. (PESSOA JR., 2003, p. 77).

O artigo de Heisenberg, segundo Pessoa Jr. (2003), além de deduzir as relações de incerteza para as grandezas observáveis q e p, faz uma interpretação física do problema por meio de um experimento de pensamento com um microscópio de raios gama, utilizado para 'ver', medir, a posição de um elétron. Como a radiação gama interage com o elétron, não se pode medir com exatidão as duas grandezas conjugadas. Assim, "[...] ele conclui que um objeto nunca possui, simultaneamente, valores exatos para as duas grandezas." (PESSOA JR., 2003, p. 78). Deste modo, ele passa de uma tese epistemológica para uma tese ontológica, ou seja, da questão sobre a possibilidade de conhecer para a questão da essência, do ser, dessas entidades em nível atômico e subatômico. Chibeni (2005), no entanto, identifica no artigo de Heisenberg três versões interpretativas para as relações de incerteza, com implicações físicas e filosóficas diferentes: a ontológica, a epistemológica e a estatística. A implicação ontológica diz respeito à considerações sobre a natureza das entidades envolvidas, ou seja, das entidades quânticas.

Em outubro do mesmo ano, 1927, ocorre a $5^{\text {a }}$ conferência ou congresso de Solvay, em Bruxelas, que, desde a sua criação em 1911, vinha reunindo os físicos mais importantes do mundo, para discutir, a cada três anos, os desenvolvimentos da teoria quântica. Ali estavam Einstein, Bohr, Heisenberg, Pauli, Dirac, entre os 32 físicos participantes. A questão das trajetórias lineares de partículas na câmara de Wilson foi ali explicitamente discutida (PESSOA JR., 2001).

Embora esteja além dos limites deste artigo uma discussão mais aprofundada a respeito, é no mínimo importante mencionar outro elemento da teoria quântica, que, 
como veremos, tem relação com o texto da peça. Jammer (2010), expressa essa questão do seguinte modo:

\begin{abstract}
Uma análise epistemológica profunda de alguns princípios da mecânica quântica parece sugerir que as concepções tradicionais de espaço e de tempo talvez não sejam o arcabouço mais adequado para descrever processos microfísicos. [...] A impossibilidade [pelo princípio da incerteza de Heisenberg] de associar a localização exata à determinação do momento bem como a dualidade ondapartícula que caracteriza a realidade física podem ser interpretadas como um desafio a uma revisão crítica das concepções de espaço e tempo normalmente aceitas. Em sua descrição das transições do elétron entre estados estacionários dentro do átomo, Niels Bohr já dissera que esses processos 'transcendem o modelo de espaço e tempo'. O problema da aplicabilidade das concepções tradicionais de espaço e tempo à física atômica foi objeto de um artigo apresentado por Louis de Broglie ao X Congresso Internacional de Filosofia [1948]. De Broglie admitiu francamente as dificuldades envolvidas no uso de nossas ideias de espaço e tempo em escala microfísica, mas também confessou que até hoje não se conhecem categorias conceituais alternativas que possam substituí-las. (JAMMER, 2010, p. 231-232)
\end{abstract}

A física, em sua dimensão discursiva, tem o mundo natural como referente e não o mundo humano. Trata-se de um discurso que se utiliza da linguagem matemática (formal) sempre associada a experimentações. Trata-se também de um discurso que explicita seus limites de validade e os objetos a que se referem seus enunciados.

Em síntese, o princípio da incerteza é elemento fundamental da teoria quântica, teoria aplicada a entidades no nível atômico e subatômico, e que provoca questionamentos e interpretações diversas sobre nosso senso comum cotidiano sobre o espaço-tempo, os limites do conhecimento, no âmbito da teoria, como intrínsecos à natureza dos objetos de que ela trata, entre esses, o limite de se experimentar a natureza completa desses objetos, que ora apresentam um comportamento como se fossem um tipo de entidade, e ora outro comportamento como se fossem outro tipo de entidade. Comportamento que, em nossa concepção e experiência cotidiana, não poderiam coexistir num mesmo objeto.

\title{
Análise da Peça
}

\section{Dispositivo analítico}

Segundo Orlandi (2008), a materialidade textual, que no caso de textos verbais, é linguística, intervém na produção de efeitos de sentido. Não de modo exclusivo, mas de modo constitutivo. A materialidade textual é o que dá corpo aos sentidos. Pensar a materialidade significa, analiticamente, descrever a forma textual, suas marcas, seus vestígios, na relação que estabelecem com os possíveis efeitos de sentidos. Esse pressuposto teórico é discutido por Silva $(2013,2019)$ em análises sobre textos que remetem às ciências na natureza. A noção de textualização traduz esse pressuposto. Assim, o que em geral se considera como conteúdo, é tratado como efeito de sentido possível e vai-se buscar a interveniência material neste possível efeito, implicando numa descrição do texto, em nível formal, articulada com uma interpretação. 
Isso, sinteticamente, diferencia uma análise da textualização de uma análise de conteúdo. No entanto, os textos em nossa sociedade apresentam formas mais ou menos estáveis, que vão além de suas características linguísticas. Essas formas são construções sociais e históricas, e, portanto, são moventes no tempo e no espaço. Isso não impede o exercício da descrição e da consideração de aspectos da forma na sua relação com possíveis efeitos de sentidos. Apenas faz com que diferentes análises possam ser produzidas sobre o mesmo objeto textual conforme as considerações sobre a forma que forem mobilizadas.

Uma análise pautada na noção de textualização deve, portanto, tomar como parte de seu dispositivo analítico subsídios teóricos que informem sobre os aspectos materiais específicos do texto em análise. No caso, temos um texto dramatúrgico, para o qual, mobilizamos autores como Ryngaert e Neves (1996) e Birkenhauer (2012), que trazem subsídios para compreender aspectos específicos deste tipo de texto. A observação, identificação destes elementos no texto foi então relacionada a possíveis efeitos de sentido dos quais esses elementos participam materialmente. $\mathrm{Na}$ análise que segue foram os seguintes elementos que encontramos na textualidade dramatúrgica da peça: gênero drama/épico, conflito, indicações cênicas, dramático/pós-dramático, tempo e espaço das ações, representação, quarta parede, que serão apresentados junto às análises.

\section{O princípio da incerteza da Física na peça em analogias}

Barad (2007) concebe esta peça teatral como um grande analogia, ou paralelo: de um lado o princípio da incerteza de Heisenberg e de outro, uma espécie de princípio da incerteza de Frayn, que consistiria sinteticamente em considerar que o fato de não ser possível ter conhecimento sobre as intenções das pessoas, não permite que possamos fazer julgamentos morais e éticos sobre suas ações. Nossas análises, no entanto, evidenciaram dois tipos de usos de analogias: as que funcionam como explicativas das ideias da física e as que se entremeiam no fio do texto, constituindo a estrutura textual dramatúrgica da peça. Este segundo caso, será detalhado no próximo subtópico. Quanto ao primeiro caso, encontramos um trecho que se refere à reação nuclear em cadeia e três trechos que se referem ao princípio da incerteza, dos quais colocamos apenas um, a título de exemplo:

Heisenberg: Escuta-me! Copenhague é um átomo. Margrethe é o seu núcleo. Está bem a escala? Dez mil a um?

Bohr: Sim, sim.

Heisenberg: E Bohr é um elétron. Ele está vagando em algum lugar da cidade na escuridão, ninguém sabe onde. Está aqui, está lá, está em toda parte e em lugar nenhum. Eu sou um fóton. Um quantum de luz. Sou enviado dentro da escuridão para encontrar Bohr. E tenho sucesso, porque vou me chocar com ele. Mas o que aconteceu? Olha, você está desacelerando! Você desviou! Já não está fazendo exatamente o mesmo que tão irritantemente estava fazendo quando me choquei! Bohr: Mas Heisenberg, Heisenberg! Também você se desviou! Se puder ver o que aconteceu com você e com sua partícula de luz, então pode calcular o que aconteceu comigo! O problema é saber o que aconteceu com você! Porque para entender como você se vê, nós temos que tratá-lo não apenas como uma partícula, e sim como uma onda. Tenho que usar não só a tua mecânica sobre as partículas, também tenho que usar a mecânica ondulatória de Schröedinger. (CARDOSO, 2015, p. 154). 
Em todos os três trechos encontrados, o comportamento e a interação entre pessoas tornam-se análogos ao comportamento e interação entre entidades quânticas, como fótons e elétrons. E a questão do limite do conhecimento sobre elas (as pessoas) torna-se análoga à questão do conhecimento físico sobre tais entidades, representado pela sua posição, velocidade. Chama a atenção a explicitação da escala atômica e subatômica. Faz parte também dessas analogias, o experimento de pensamento usando um microscópio (num dos outros trechos), que de fato aparece no artigo original de Heisenberg (1983). Na verdade, todos os casos podem ser compreendidos como experiências de pensamento, análogas às utilizadas pelos físicos. Também foi mobilizado na analogia o experimento da câmara de nuvens, bastante discutido no Congresso de Solvay de 1927, que teve como tema Elétrons e fótons, e do qual participaram Bohr, Heisenberg, como já mencionamos.

Destacamos essas analogias por incorporarem mais explicitamente elementos do discurso físico: fótons e elétrons, experimentos de pensamento, experimentos de laboratório, e outros elementos da teoria quântica, como dualidade partículaonda, a interação entre partículas (espalhamento) e, o princípio da incerteza. Além disso, representa mais um indício material do sistema analógico geral que estrutura a temática da peça: comportamento, interação e natureza de elétrons e fótons análogos ao comportamento, interação e natureza das pessoas, quanto às suas ações e intenções.

Veremos, a seguir, o texto em mais detalhes em seus aspectos materiais específicos enquanto texto dramatúrgico, e que caracterizam uma textualização do princípio da incerteza da Física e seus deslocamentos.

\section{A textualização teatral: entre o dramático e pós-dramático}

A identificação de metáforas e analogias, no entanto, não dá conta das especificidades da textualização dramatúrgica. Buscamos, assim, por um diálogo teórico que permitisse, analiticamente, abarcar a textualidade, ou seja, aspectos da forma textual, no que esta participa dos efeitos de sentido, para, posteriormente, tecer considerações sobre as relações com a Física estabelecidas pelo texto. Utilizamos como suporte trabalhos como os de Ball (2005), Birkenhauer, (2012), Ryngaert e Neves (1996), entre outros.

Pensar o discurso artístico, e mais especificamente, a materialidade do texto teatral, se faz necessário para compreender fatores cruciais no processo de produção de sentidos e nas relações que este texto estabelece com o conhecimento científico, no caso, a Teoria Quântica (TQ) e, particularmente nesta análise, o princípio da incerteza. Dessa forma, olhamos o texto teatral enquanto um meio de circulação cultural popular do discurso científico, com suas especificidades, propiciando elementos para futuras construções de mediações de leitura que levem em conta as relações entre forma e conteúdo, contribuindo para romper com uma apropriação meramente instrumental de um artefato cultural.

Para Ryngaert e Neves (1996, p. 35) "[...] toda obra dramática pode ser apreendida, em primeiro lugar, na sua materialidade, no modo como a sua organização de superfície se apresenta sob forma de obra escrita". No entanto, da Poética de Aristóteles aos estudos do teatro contemporâneo, muito se discute sobre quais seriam as principais características do texto para que seja entendido como texto teatral. 
Considerações acerca do estilo de escrita e dos modos de enunciação separaram, inicialmente, os textos teatrais em gêneros (épico, dramático, pós-dramático, etc.). De acordo com Ryngaert e Neves (1996, p. 7), "[...] os gêneros não concernem apenas às formas da escrita, mas também, por intermédio das personagens em ação, à natureza dos temas tratados".

Nesta perspectiva, Copenhagen apresenta uma incerteza (indefinição) estrutural intrínseca quanto a seu gênero enquanto texto teatral, oscilando entre o épico (narrativa de maior extensão) e o dramático (diálogo entre personagens atuantes sem interferências externas), entre memórias narradas individualmente, como na fala de Margrethe: "E Niels decide, de repente amá-lo novamente, apesar de tudo" (CARDOSO, 2015, p. 124), e diálogos construídos em jogos temporais também ambíguos. Em toda extensão do texto há oscilações entre narrativas, que se configuram ora como pensamentos, ora como lembranças, ora como opiniões faladas, como num monólogo ou como um diálogo com o público, e ora como diálogos que constroem o encontro das três personagens.

\footnotetext{
Bohr: É certo que ele sabe que o estão vigiando. Tem que ter cuidado com o que diz. Mas bem se poderia se cuidar com o que diz.

Margrethe: Tem que se cuidar ou não o vão deixar sair do país de novo.

Heisenberg: Me pergunto se imaginam o quão difícil foi conseguir permissão para vir. Os humilhantes pedidos ao partido, os poucos recursos para "a festa", os esforços desgastantes para que nossos amigos na chancelaria usassem suas influências. Margrethe: Como ele parece? Será que ele mudou muito?

Bohr: Um pouco mais velho (CARDOSO, 2015, p. 115).
}

No trecho anterior, no intermédio do diálogo entre Bohr e Margrethe, aparece uma fala de Heisenberg claramente direcionada ao púbico, e não aos outros personagens, como um comentário narrado de uma lembrança. Da mesma forma, no trecho a seguir podemos perceber também na fala de Heisenberg uma breve fuga da conversa direta entre os personagens. Falas que soam tanto como solilóquios ou pensamentos interiores, quanto como narrativas históricas sobre personagens de um épico:

Bohr: Mas era um físico excepcional. E quanto mais eu penso, mais me convenço de que Heisenberg foi o melhor.

Heisenberg: Quem foi Bohr? Ele foi o primeiro, o pai de todos nós! Tudo o que fizemos foi baseado em sua grande intuição!

Bohr: Pensar que veio trabalhar comigo em 1924... (CARDOSO, 2015, p. 113).

Ainda sobre a oscilação entre diálogos (drama) e narrativas (épico), destacamos uma parte inteiramente narrada, que tem no público/leitor um endereçamento direto:

Margrethe: Silêncio. Em que pensará? Em sua vida? Na nossa? Heisenberg: Silêncio. E é claro que eles estão pensando novamente em seus filhos. (CARDOSO, 2015, p. 127).

Falas que soam como de um narrador, independente dos personagens que as pronunciam. Assim como no trecho:

Margrethe: O que Niels disse a Heisenberg? O que Niels respondeu? A pessoa que mais queria saber era o próprio Heisenberg! (CARDOSO, 2015, p. 131).

Para Ryngaert e Neves (1996, p. 13) "[...] na forma épica, é comum tomar a sala por testemunha, sem passar pelo simulacro de um diálogo", já na forma dramática, tem-se "uma obra que 'imita' pessoas que fazem alguma coisa" (RYNGAERT; NEVES, 1996, p. 9), 
trazendo assim o conceito de ação dramática. Nos trechos que destacamos, essas formas se misturam. Copenhagen possui ação dramática? Como ela se caracteriza em meio aos diálogos e narrativas? A ação dramática no texto está internalizada na percepção do leitor/público. Tudo isso, torna-se incerto.

Temos uma relação metafórica com a teoria quântica, e o princípio da incerteza, quanto à natureza das entidades, a questão da ontologia, deslocada e trabalhada na própria indefinição do ser do texto quanto ao seu gênero. Ora dramático, ora narrativo; nem completamente dramático, nem completamente narrativo. Metaforização estrutural da indefinição ontológica das entidades da teoria quântica: ondas e partículas. Mas metaforização também da relação entre público (observadores/julgadores de Heisenberg) e o caso abordado pela encenação dos atores (observáveis/ações de Heisenberg em relação à bomba atômica alemã).

Ball (2005), no entanto, argumenta que entre aqueles que fazem, leem e comentam sobre teatro, o ponto de convergência para a caracterização do drama se dá em torno da ideia de conflito, pois é a partir do conflito que as personagens agem. A ação ou ação dramática, segundo Pallottini (1988, p. 9), "[...] é a ação de quem, no drama, vai em busca dos seus objetivos consciente do que quer". Para Ball (2005, p. 23) "[...] a ação é um encadeamento de acontecimentos, ou seja, a ação ocorre quando faz com que uma outra coisa aconteça".

Nesta busca por um objetivo, que desencadeia ações e faz o enredo se desenrolar, surgem resistências que se caracterizam como um conflito dramático; para Pallottini (1988, p. 48) "o conflito é o cerne de toda peça de teatro". É por esse quadro de desejo, ação e conflito com que o leitor/plateia se identifica e se comove. Essa personificação das angústias e conflitos humanos que despertam emoções é caracterizada como verossimilhança dramática.

Para Ryngaert e Neves (1996, p. 64) "[...] o conflito existe quando um indivíduo é contrariado por um outro (uma personagem) ou quando se depara com um obstáculo social, psicológico, moral", e afirma mais adiante que, do ponto de vista da mecânica de uma peça, o conflito comanda o fio condutor.

O conflito em Copenhagen não está nas falas enunciadas. Ele se estabelece em torno da memória dos três personagens mortos, contra suas lembranças, contra si mesmos, que buscam a resposta sobre o porquê da visita de Heisenberg a Bohr em 1941, em plena Segunda Guerra Mundial, e apresentam, cada um à sua maneira, na forma de um efeito-lembrança, suas versões desse encontro enigmático vivido por eles em vida. O que motivou Heisenberg a visitá-los? Qual o assunto da conversa? As possibilidades são construídas em dois atos, de forma a criarem e se recriam situações de acordo com suas múltiplas perspectivas. O conflito é caracterizado nesta peça pela própria incerteza. Ele não reside no que os personagens estão fazendo na cena, mas sobre o que teriam feito ou não feito, o que os teria motivado. Enfim, sobre algo que não se sabe e nunca se saberá ao certo. E sobre o qual nosso conhecimento completo e preciso é impossível. Um limite epistemológico, associado a um problema ético. Eis o conflito deste texto. Ou seja, outra relação metafórica com a teoria quântica, o princípio da incerteza, como já apontamos.

Em meio às incertezas da memória, surgem outros dilemas que conduzem a trama e aprofundam e constituem outras facetas do conflito-chave da peça: as posições ética e moral de Heisenberg como cientista dentro do programa de pesquisa em Física 
nuclear da Alemanha então governada por Hitler durante a Segunda Guerra Mundial. Esse conflito se desenvolve, entre outros aspectos, sob a construção de uma espécie de dualidade em torno de Heisenberg. Esta é indicada já no início do texto, quando Margrethe e Bohr discutem sobre receberem um alemão como visita.

\author{
Margrethe: Mas porque ele veio? O que está tentando dizer? \\ Bohr: No fundo creio que é muito simples: queria conversar. \\ Margrethe: Conversar? Com o inimigo? No meio da guerra? \\ Bohr: Margrethe, meu amor, não éramos inimigos. \\ Margrethe: Estamos falando de 1941! \\ Bohr: Heisenberg era nosso amigo! \\ Margrethe: Heisenberg era alemão! Nós éramos dinamarqueses! Os alemães tinham \\ ocupado o nosso país. Eu nunca vi você tão irritado com alguém como naquela \\ noite com Heisenberg! (CARDOSO, 2015, p. 112, grifos nossos).
}

Quem era Heisenberg? Outra incerteza, e vários efeitos de dualidades, que não se resolvem numa direção única, várias faces complementares apesar de parecerem antagônicas ou substancialmente diferentes: amigo/inimigo, cientista/alemão, e em outros trechos, filho/colaborador. O ser do Heisenberg é inseparável de como se observa o contexto. No mesmo patamar de importância, identificamos os embates relacionados a problemas éticos e morais, ligados à inseparabilidade entre a produção científica e seu contexto histórico e político.

A questão ontológica, importante problema da teoria quântica, ligada ao princípio da incerteza, como apontamos anteriormente, aparece agora na natureza dos personagens, sempre caracterizados por uma dualidade, metaforizando estruturalmente a dualidade partícula-onda.

A incerteza das memórias tem papel fundamental no desenrolar do conflito, que, nas falas finais da peça, assim como na vida real, acaba sem resolução, sem certezas:

\footnotetext{
Bohr: Quando as decisões, grandes ou pequenas, não se voltam a tomar nunca mais. Quando não há mais incerteza, porque não haverá mais conhecimento. Margrethe: E quando todos nossos olhos se tiverem fechados, quando até os nossos fantasmas se tenham ido... o que restará do nosso adorado mundo? De nosso arruinado, desonrado e adorado mundo?

Heisenberg: Mas enquanto isso, neste meio tempo precioso aí está. As árvores do parque. Os lugares amados. Os nossos filhos e os filhos dos nossos filhos. Preservados possivelmente, por aquele momento tão breve em Copenhague. Por algum acontecimento será encontrada ou definida em todo. Por esse último núcleo de incerteza que se encontra no coração de tudo o que existe. (CARDOSO, 2015, p. 173).
}

No que diz respeito ao desenvolvimento do conflito, em termos estruturais, Copenhagen apresenta uma característica diferenciadora em relação a outros textos teatrais: o texto não faz o uso de indicações cênicas, as chamadas didascálias: informações de ações, mudanças de entonação, mudanças de plano, entradas e saídas de atores, direcionamentos de falas, entre outros, como no exemplo (destaques grifados) retirado de outra famosa peça que faz referência à física, A vida de Galileu, de Bertold Brecht,

Galileu (pega uma maçã na mesa): Bom. Isto é a Terra.

Andrea: Ah, não, seu Galileu, não pegue esses exemplos. Assim o senhor sempre se sai bem.

Galileu (pondo a maçã no lugar outra vez): Você é quem sabe. (BRECHT, 1991, p. 8, grifos nossos). 
No entanto, a fala dramática enquanto função comunicativa possibilita dois sistemas: o interno e o externo. Nesta duplicidade enunciativa, o sistema interno diz respeito à comunicação entre as personagens, e o externo diz respeito a indicações que extrapolam a fala, o texto coadjuvante, as intenções comunicativas do autor. Copenhagen é escrito de forma corrida, o texto original é composto somente por falas que devem ser pronunciadas pelas personagens, ora com efeito de diálogo, ora com efeito de narrativa. As personagens são elas mesmas narradoras, comentadoras e agentes da trama. Para Ryngaert e Neves (1996), trata-se de manter a ambiguidade do texto, não impondo modelo à representação. As palavras dos personagens não ganham um quadro figurativo ou sistema de desempenho. Não são colocadas indicações de cenário, vestuário, disposições. Nenhuma indicação cênica. Sob esta ótica, dois pontos se destacam na leitura da obra: a forma como o diálogo é estruturado, rompendo com alguns elementos do drama tradicional; e o meio pelo qual a percepção temporal é construída no texto, o tempo em Copenhagen é indeterminado. Bohr, Heisenberg e Margrethe conversam ora no presente pós-morte, revivendo lembranças, ora no passado vivido, como se fosse possível alterar os fatos e sem nenhuma indicação explícita de mudança, conforme os trechos:

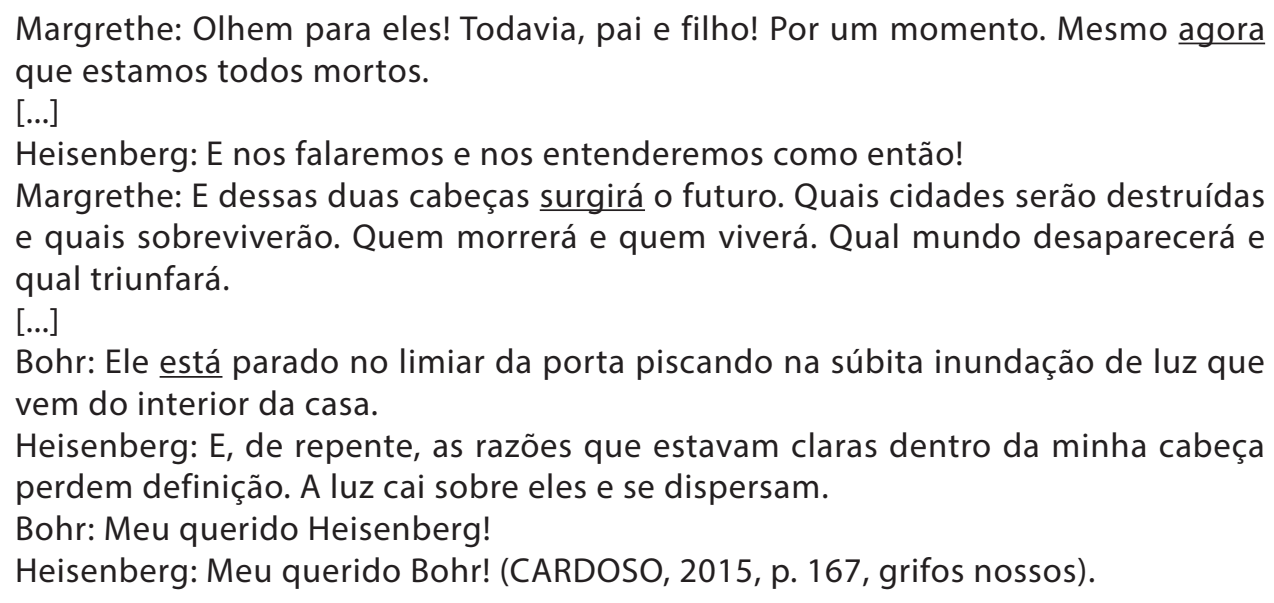

Estas características salientam outra indefinição: a peça possui tanto aspectos de um texto dramático como de um texto pós-dramático. Um ponto fundamental no teatro pós-dramático, é o rompimento com a quarta parede, que ressignifica o papel do público no teatro. Para Birkenhauer (2012, p. 185), no teatro dramático "[...] o espectador é endereçado enquanto observador clandestino, que é excluído do acontecimento". Já no pós-dramático, segundo Barnett (2005, p. 140, tradução nossa) este "[...] se torna um teatro de linguagem em que a palavra é liberada da limitação representacional", em geral marcada por um tempo e um espaço imprecisos, os personagens se transformam em portadores de texto. Barnett (2005, p. 139, tradução nossa) considera "[...] o texto [Copenhagen] visto como um híbrido, em algum lugar entre o dramático e o pósdramático, definido, como é, em uma vida fictícia após a morte onde as categorias humanas convencionais já não funcionam". Os personagens e suas ações são e não são os mesmos do nosso mundo cotidiano. Embora sejam personagens, não estão emoldurados por uma representação. Para Barnett (2005, p. 140, tradução nossa) "[...] o teatro pós-dramático não estrutura o tempo". Para o autor, "[...] o tempo no teatro pós-dramático é mais parecido com o 'tempo em sonho' em oposição ao 'tempo na vida cotidiana'" (BARNETT, 2005, p. 140, tradução nossa). 
Eis outra relação metafórica com a teoria quântica e com o princípio da incerteza, relacionada à questão da medição e do observador, já que, como vimos, o que é medido tem relação com o experimento preparado para a medição, que 'revela' apenas uma das facetas da natureza e comportamento do objeto. A questão do observador, tão importante na teoria quântica, na peça tem como análogo a relação do público com os atores e o rompimento da 'quarta parede'.

O tempo em Copenhagen estabelecido enquanto tempo pós-vida, fora da nossa percepção comum, permite que as personagens se desloquem, sem trajetória, temporalmente nos eventos, revivendo e refletindo sobre suas vidas. Possibilidades para o diálogo havido entre Bohr e Heisenberg no encontro de 1941 aparecem sem a construção de uma situação representacional próxima de um documentário histórico ou de ficções históricas baseadas em fatos reais, bastante comuns no cinema. Bohr, Margrethe e Heisenberg (fictícios) são, ao mesmo tempo, observadores e observáveis. São capazes de testar possibilidades e reconstruir os eventos, de maneira não-representacional, mas jamais com a precisão.

Temos, assim, outra referência à física quântica, produzida pela forma do texto teatral, já que na teoria quântica, como vimos, a questão do tempo e do espaço não pode ser compreendida como representamos os eventos em nosso mundo cotidiano.

\section{Outras incertezas na textualização teatral}

Percebemos em Copenhagen outros efeitos de sentido de incerteza relacionados: ao princípio físico, propriamente dito, onde o tema é abordado explicitamente através de metáforas e analogias; mas também incertezas relacionadas ao posicionamento (ético e moral) de Heisenberg durante a guerra; incertezas sobre o enredo da conversa de 1941; acerca do papel de Margrethe na trama. A análise do texto mostrou que a peça trabalha com uma polissemia de efeitos de sentido de incerteza como eixo e tema estruturantes da obra.

\section{Incertezas éticas}

Dos fatos históricos, o posicionamento político de Heisenberg traz em si uma dualidade marcante. A produção da bomba nuclear permite elaborar questionamentos sobre a produção científica durante a Segunda Guerra Mundial, e mais especificamente, questionamentos sobre os limites e relações entre Física e política, geopolítica, poder, Estado. Produziam-se conhecimentos científicos e fazia-se política.

Naquele contexto, Heisenberg era amigo e/ou inimigo? Contribuiu para/ou atrapalhou o programa nuclear alemão? A conversa do encontro de 1941 foi sobre Física e/ou política? É possível fazer tal separação? Quais os limites e as consequências das descobertas e produções científicas sobre a sociedade? Qual a contribuição de Bohr na construção da bomba norte-americana? Enquanto Heisenberg é malvisto por coordenar o programa nuclear alemão, sendo o homem que ofereceria uma bomba a Hitler, Bohr tem, sabidamente, participação importante no programa nuclear dos aliados (Projeto Manhattan), liderado cientificamente por Oppenheimer. O texto joga com esse fato, induzindo as incertezas quanto à responsabilidade moral de cada um. A indeterminação motivacional, intencional dos fatos se torna um dispositivo dramático/pós-dramático 
no texto. Indeterminação que não estaria ligada a um desconhecimento dos fatos históricos, mas que seria intrínseca ao objeto, à condição humana na História.

\section{Incertezas de Margrethe}

Se Heisenberg e Bohr são protagonistas e temas da história, qual seria então a função de Margrethe na obra? Não há uma resposta claramente determinada, configurando-se como mais uma incerteza, uma indefinição a ser apontada. Ora ela aparece apenas observando e comentando os eventos, ora suas falas refletem pensamentos aleatórios ou falas provocativas, ora suas falas têm a função das didascálias e, às vezes, ela é colocada no papel de leiga, fazendo com que os físicos utilizem linguagem simples para explicar conceitos científicos, como o Salviati dos Diálogos de Galileo Galilei, obra científica que, aliás, tem algo de forma teatral, na medida em que é composta por três personagens.

Evidenciamos essas múltiplas funções nos trechos a seguir:

Bohr: Meu querido Heisenberg! Heisenberg: Meu querido Bohr! Bohr: Entre, entre...

Margrethe: E, claro, apenas se vêem, se avivam as velhas chamas (CARDOSO, 2015, p. 118).

[...]

Bohr: Muito bem. Vamos começar do princípio. Não há homens da Gestapo nas sombras. Não há oficinal da inteligência britânica. Ninguém nos observa.

Margrethe: Só eu!

Bohr: Só Margrethe. Vamos deixar tudo claro para ela! Você sabe que eu acredito fervorosamente que não fazemos ciência para nós, que a fazemos isso para poder explicá-la aos outros...

Heisenberg: Em linguagem simples (CARDOSO, 2015, p. 134).

[...]

Margrethe: Silêncio novamente. Agora eu começo a sentir pena! Sentado aqui, completamente sozinho, de frente para nós dois, em um país onde o odeia. Agora o vejo mais jovem, como o cara que veio aqui pela primeira vez em 1924. Tímido e arrogante e com necessidade de que o queiram. E, sim, é triste, porque Niels o amava! Foi um pai para ele (CARDOSO, 2015, p. 120).

[...]

Margrethe: E Niels decide, de repente amá-lo novamente, apesar de tudo. Por quê? O que aconteceu? Foi a lembrança daquele dia de verão em Göttingen? De qualquer forma, quando nos sentamos para jantar, as cinzas foram acesas novamente (CARDOSO, 2015, p. 124).

Em muitos trechos é possível identificar a posição dela enquanto observadora (não neutro) que, analogamente ao contexto da Física Quântica, interfere no resultado do experimento, escolhe o que quer ver, possibilitando uma analogia entre os observadores/observáveis. Margrethe é, de certa forma, o público (observador) dentro da peça, lembrando uma divulgação científica.

\section{Incertezas espaço-temporais}

A passagem e localização espaço-temporal no texto, como já apontamos, é complexa e também incerta. A conversa se desenvolve em um tempo não preciso, num encontro pós-morte entre os protagonistas, em local igualmente indeterminado. Os personagens estão mortos, mas há trechos em que parecem vivos. Em vários momentos há dois tempos verbais numa mesma frase ou sequência. 
O que era memória vira presente, e eles revivem o passado, sendo observadores de si mesmos. O tempo em Copenhagen se fixa no tempo do aqui e agora, no tempo da encenação/leitura. O tempo do inevitável. As noções realistas de localidade e temporalidade são rompidas no/pelo texto, num distanciamento da representação:

Heisenberg: A memória é tão curiosa, na cabeça o passado se torna presente! Setembro de 1941, Copenhagen! E imediatamente aqui estou, descendo do trem noturno que vem de Berlim, com o meu colega Weizsäcker!... (CARDOSO, 2015, p. 114).

\section{Textualização teatral da incerteza e o princípio da incerteza na Física}

Temos assim, uma série de aspectos que trabalham no fio da própria textualidade, na sua estrutura e especificidades enquanto texto teatral, efeitos de incerteza. Incerteza quanto às personagens (incertezas ontológicas), a ausência de representalidade da realidade espaço-temporal, como molduras pré-definidas e definidoras, o que coloca o/a leitor/a (espectador/a) na posição do observador/a dos fatos, sem ter jamais conhecimento certo, preciso, sobre os personagens, sua natureza e motivações. Sem dúvida, o tema da incerteza pode ser considerado estruturante deste texto teatral. Sem dúvida, também que, se este não é certamente o princípio da incerteza da Física, este tema teve na física sua inspiração e uma inspiração aprofundada, pois incorpora, na forma teatral dramatúrgica, elementos relevantes e não triviais correlatos ao princípio da incerteza da física.

As incertezas aqui recaem sobre outro tipo de entidade, que não as entidades do mundo natural, atômico e subatômico, o mundo da microfísica, tais como as abordadas pela teoria quântica da física. Aqui, as incertezas recaem sobre a entidade 'ser humano', pertencendo, portanto, aos campos da ética e da moral: de elétrons e fótons para pessoas, homens e mulheres, de uma ontologia/epistemologia da natureza para uma ontologia/epistemologia de nós mesmos.

\section{Considerações Finais}

Copenhagen, certamente, é um texto riquíssimo para o ensino de física, não pela sua fidedignidade histórica ou conceitual, mas no mínimo pelo conjunto de aspectos da teoria quântica que mobiliza para sua construção, mesmo que por analogias e de forma metafórica. O texto entrelaça aspectos históricos gerais, da história da ciência, das relações entre ciência e política, geopolítica e poder do Estado, assim como relações entre ciência e ética, aspectos cuja importância para o ensino de física tem sido indicada por diversas pesquisas (PAGLIARINI; ALMEIDA, 2016; SILVA; ALMEIDA, 2011). São diversos os elementos observados que podem propiciar discussões sobre teoria quântica em seus aspectos conceituais fundamentais, filosóficos e históricos, e éticos e políticos, numa abordagem histórico e cultural da Física (MOURA; GUERRA, 2016). E outras análises merecem ser realizadas explorando mais detidamente esses elementos e seus potenciais para a educação científica em física.

Quanto à análise realizada, a importância, a nosso ver, de dar visibilidade à forma, e não apenas ao conteúdo das falas, propiciada pela noção de textualização, reside no fato de que a forma é conteúdo, como pudemos ver pelas análises. No entanto, essa especificidade do dispositivo analítico que utilizamos, permite ainda outras 
conclusões, que revelam indícios de um fenômeno cultural mais amplo ainda pouco compreendido: as inúmeras e tão diversificadas apropriações da física moderna e contemporânea em nossa cultura popular. E isso certamente tem a ver com as metáforas.

Como vimos, há trechos no texto em que se utilizam analogias e metáforas para explicações explícitas de ideias físicas. Tais trechos devem ser diferenciados da peça como um todo. Eles remetem a estratégias mais comuns presentes em textos didáticos e de divulgação científica, no sentido de comunicar uma ideia científica para um público mais amplo. Mas a peça como um todo, mesmo que se tenham observado inúmeros efeitos de sentido sobre incerteza, o que nos levou a concluir ser essa ideia um elemento estruturante deste texto teatral, não pode ser considerada como divulgação científica ou peça didática. Uma metaforização didática e de divulgação científica possuem um compromisso teórico, conceitual e epistemológico com o conhecimento que didatiza ou divulga, populariza.E, portanto, está sujeita, merecida e adequadamente, a considerações dessa natureza.

Mas o trabalho metafórico da peça em sua forma/conteúdo em relação à ideia de incerteza, que certamente tem inspiração temática no princípio da incerteza da física, se coloca, no entanto, nos planos ético e moral e não no plano do mundo natural. A ideia de incerteza adquire um aspecto estruturante na medida em que se observa uma relação com diversos elementos da forma textual artística em seus detalhes materiais e estruturais, característicos de uma peça teatral, e, porque é elemento que estrutura a construção, as ações e ideias e interações entre os personagens.

Esta diferença é um aspecto importante cuja observação e tratamento em situações de ensino pode ter um papel formativo importante. São inúmeros os exemplos que podemos encontrar desse tipo de mecanismo geral de metaforização da ciência na cultura popular. As metaforizações desse texto teatral são, no entanto, diferentes das didáticas e da divulgação científica.

Uma metaforização como a que a peça produziu sobre a ideia de incerteza, gerando, em linguagem textual teatral, ou dramatúrgica, uma espécie de princípio de incerteza ético e moral (BARAD, 2007), tem uma relação com a física apenas como inspiração para a construção de um dispositivo estético específico na linguagem deste artefato artístico-cultural.

Pensamos ser importante uma atenção especial a esse tipo de fenômeno em que a teoria quântica parece ser especial e intensamente utilizada em nossa cultura popular. Trata-se da tomada de uma teoria sobre a natureza para uma teorização popular sobre o ser humano. Pensamos que esse deslocamento cultural, epistemológico, ontológico do campo da natureza para o campo da ética, que aqui apenas deixamos apontado, merece pesquisas específicas e mais aprofundadas, assim como sobre suas implicações educacionais para a construção de subjetividades, tema que já vem sendo discutido atualmente (BAZZUL, 2015).

\section{Referências}

ARAUJO, G. A. D. O teatro na educação científica e tecnológica: sentidos, interpretação e produção em uma peça teatral que conta uma história de/sobre ciência. 2014. 141 f. Dissertação (Mestrado em Educação Científica e Tecnológica) - Universidade Federal de Santa Catarina, Florianópolis, 2014. Disponível em: https://repositorio.ufsc.br/handle/123456789/129161. Acesso em: 28 jan. 2021. 
ASSIS, A.; WHITAKER, D. A.; WHITAKER, M. A.; CARVALHO, F. C. Metamorfose na sala de aula: desfazendo estigmas na disciplina de física a partir do teatro. Caderno Brasileiro de Ensino de Física, Florianópolis, v. 33-50, n. 1, p. 33, 2016. DOI: https://doi.org/10.5007/21757941.2016v33n1p33.

BALL, D. Para trás e para frente: um guia para leitura de peças teatrais. São Paulo: Perspectiva, 2005.

BARAD, K. Meeting the universe halfway: quantum physics and the entanglement of matter and meaning. Durhan: Duke University Press, 2007.

BARNETT, D. Reading and performing uncertainty: Michael Frayn's Copenhagen and the postdramatic theatre. Theatre Research International, Cambridge, v. 30, n. 2, p. 139-149, 2005.

BAYM, G. The uncertainty principals: Bohr and Heisenberg from Copenhagen (the city) to Copenhagen (the play). Urbana: University of Illinois, 2005. Disponível em: https://physics.illinois. edu/people/baym/copenhagen.pdf. Acesso em: 26 jun. 2020.

BAZZUL, J. Tracing "ethical subjectivities" in science education: how biology textbooks can frame ethico-political choices for students. Research in Science Education, Dordrecht, v. 45, p. 23-40, 2015. DOI: https://doi.org/10.1007/s11165-014-9411-4.

BIRKENHAUER, T. Entre fala e língua, drama e texto: reflexões acerca de uma discussão contemporânea. Urdimento: revista de estudos em artes cênicas, Florianópolis, v. 1, n. 18, p. 181188, 2012. DOI: https://doi.org/10.5965/1414573101182012181.

BRAGA, M. A. B.; MEDINA, M. N. O teatro como ferramenta de aprendizagem da física e de problematização da natureza da ciência. Caderno Brasileiro de Ensino de Física, Florianópolis, v. 27, n. 2, p. 313-333, 2010.

BRECHT, B. A vida de Galileu. Rio de Janeiro: Paz e Terra, 1991.

CARDOSO, F. L. M. Versão brasileira da peça de teatro Copenhagen (de Michael Frayn) para fins didáticos. Revista Hipótese, Itapetininga, v. 1, n. 1, p. 109-174, 2015.

CHIBENI, S. S. Certezas e incertezas sobre as relações de Heisenberg. Revista Brasileira de Ensino de Física, São Paulo, v. 27, n. 2, p. 181-192, 2005.

EINSTEIN, A. Sobre um ponto de vista heurístico a respeito da produção e transformação da luz. In: STACHEL, J. (org.). O ano miraculoso de Einstein: cinco artigos que mudaram a face da física. 2. ed. Rio de Janeiro: Editora da UFRJ, 2005. p. 201-222.

GIMENEZ, H. Teatro científico: uma ferramenta didática para o ensino de física. 2013. Dissertação (Mestrado em Ensino de Ciências) - Universidade Federal de Mato Grosso, Cuiabá, 2013.

HEISENBERG, W. The physical content of quantum kinematics and mechanics. In: WHEELER, J. A.; ZUREK, W. H. (org.). Quantum theory and measurement. Princeton: Princeton University Press, 1983. p. 62-84.

JAMMER, M. Conceitos de espaço: a história das teorias do espaço na física. Rio de Janeiro: Contratempo, 2010.

MARTINS, R. A.; ROSA, P. S. História da teoria quântica: a dualidade onda-partícula, de Einstein a De Broglie. São Paulo: Livraria da Física, 2014.

MOREIRA, L. M. Oxigênio: uma abordagem filosófica visando discussões acerca da educação em ciências - parte 1: poder e ambição. Ciência \& Educação, Bauru, v. 18, n. 4, p. 803-818, 2012. DOI: http://dx.doi.org/10.1590/S1516-73132012000400005.

MOURA, C.; GUERRA, A. História cultural da ciência: um caminho possível para a discussão sobre as práticas científicas no ensino de ciências? Revista Brasileira de Pesquisa em Educação em Ciências, Belo Horizonte, v. 16, n. 3, p. 725-748, 2016. 
OLIVEIRA, L. M.; GOMES, M. L. Einstein e a relatividade entram em cena: diálogos sobre o teatro na escola e um ensino de física criativo. Caderno Brasileiro de Ensino de Física, Florianópolis, v. 33, n. 3, p. 943-961, 2016.

ORLANDI, E. P. Discurso e texto: formulação e circulação dos sentidos. 3. ed. Campinas: Pontes, 2008.

PAGLIARINI, C. R.; ALMEIDA, M. J. P. M. Leituras por alunos do ensino médio de textos de cientistas sobre o início da física quântica. Ciência \& Educação, Bauru, v. 22, n. 2, p. 299-317, 2016. DOI: http://dx.doi.org/10.1590/1516-731320160020003.

PALLOTTINI, R. Introdução à dramaturgia. São Paulo: Ática, 1988.

PALMA, C. Arte e ciência no palco. História, Ciências, Saúde - Manguinhos, Rio de Janeiro, v. 13, sup., p. 233-246, 2006. DOI: http://dx.doi.org/10.1590/S0104-59702006000500014.

PESSOA JR., O. Conceitos de física quântica. São Paulo: Livraria da Física, 2003. v. 1.

PESSOA JR., O. Discussão geral das novas idéias formuladas: $5^{\circ}$ congresso de Solvay (1927). In: PESSOA JR., O. (org.) Fundamentos da física 2: simpósio David Bohm. São Paulo: Livraria da Física, 2001. p. 139-172.

RYNGAERT, J.-P.; NEVES, P. Introdução à análise do teatro. São Paulo: Martins Fontes, 1996.

SILVA, H. C. Discurso e epistemologia: um olhar sobre as relações entre texto, ciência e escola a partir da noção de textualização. In: CASSIANI, S.; SILVA, H. C.; PIERSON, A. H. C. (org.). Olhares para o ENEM na educação científica e tecnológica. Araraquara, SP: Junqueira \& Marin, 2013. p. 241269.

SILVA, H. C. A noção de textualização do conhecimento científico: veredas pelos estudos da ciência, conexões pela educação em ciências. In: SILVA, H. C. (org.). Ciências, seus textos e linguagens: ensaios sobre circulação e textualização de conhecimentos científicos e matemáticos. Curitiba: CRV, 2019. p. 15-34.

SILVA, A. C.; ALMEIDA, M. J. P. M. Física quântica no ensino médio: o que dizem as pesquisas. Caderno Brasileiro de Ensino de Física, Florianópolis, v. 28, n. 3, p. 624-652, 2011. DOI: https://doi. org/10.5007/2175-7941.2011v28n3p624.

SILVEIRA, A. F. O teatro como instrumento de humanização e divulgação da ciência: um estudo do texto ao ato da obra Copenhague de Michael Frayn. 2011. Tese (Doutorado em Ensino, Filosofia e História das Ciências) - Universidade Federal da Bahia, Salvador, 2011.

SILVEIRA, A. F.; RIBEIRO FILHO, A.; SILVA, A. P. B. Os princípios de complementaridade e de incerteza na obra Copenhague de Michael Frayn: a arte e a teoria quântica. In: FREIRE JR., O.; PESSOA JR., O.; BROMBERG, J. L. Teoria quântica: estudos históricos e implicações culturais. Campina Grande: EDUEPB, 2011. p. 321-337. Disponível em: http://books.scielo.org/id/xwhf5. Acesso em: 30 jul. 2020.

STEWART, V. A Theatre of uncertainties: science and history in Michael Frayn's 'Copenhagen'. New Theatre Quarterly, Cambridge, v. 15, n. 4, p. 301-307, 1999. 